\title{
Upaya konselor dalam mengatasi permasalahan anak jalanan
}

\author{
Bertha Mazela Febriani ${ }^{1 *}$, Lidya Puspita ${ }^{2}$, Sari $^{3}$, Evan Pratama ${ }^{4}$ \\ ${ }^{1234}$ Universitas Negeri Padang \\ *) Correspondence email : bmazela@yahoo.com
}

\begin{abstract}
Street Children Are Children whose Daily Life Is On The Road To Make A Living. The existence of a child on the street, something very dilemmatic. Lust Seeks Money To Get The Money That Makes It Survive, The Presence Of Children On The Street Often Disrupts Public Order And Their Rights As Children For Affection, Education And Livelihoods That Are Worth Not Separated Again Can Ruin Their Life In The Future. They Are Social Groups That Are Very Vulnerable From Physical Children, Emotions, Or Other Social Violence. Street Children, Like Children, Born With Talents And Interests, Nothing And Develop Because Of The State Of Experiences. And Have Hope or Ideas That Are So Great for Himself.
\end{abstract}

Keywords: street children

Article History: Received on 09/10/2017; Revised on 12/11/2017; Accepted on 23/11/2017; Published Online: 22/12/2017 distribution, and reproduction in any medium, provided the original work is properly cited. C2017 by author.

\section{INTRODUCTION}

Metodelogi penelitian ini menggunakan penelitian berbasis studi literature/studi pustaka yang dlakukan dengan mengkaji dan menggali berbagai teori dan praksis melalui literature memalui buku, junal ilmiah, dan artikel serta fakta yang ada dimasyarakat. Pertambahan penduduk yang begitu pesat sebagai produk dari kemajuan teknologi, mekanisasi, industrialisasi dan urbanisasi memunculkan masyarakat modern yang serba kompleks dan sudah pasti banyak menimbulkan berbagai macam masalah sosial khususnya anak jalanan (anjal)

Pendidikan merupakan hal yang terpenting dalam membantu perkembangan siswa, kerena pendidikan merupakan proses di dalam kehidupan untuk mengembangkan diri agar dapat melanjutkan kehidupan, dengan cara yaitu belajar. Hal ini tercantum pada Undang-undang nomor 20 tahun 2003 tentang system pendidikan Nasional pasal 3 bahwa :Pendidikan Nasional berfungsi mengembangkan kemampuan dan membentuk watak serta peradaban bangsa yang bermartabat dalam rangka mencerdaskan kehidupan bangsa, bertujuan untuk berkembangnya potensi peserta didik agar menjadi manusia yang beriman dan bertakwa kepada Tuhan Yang Maha Esa, berakhlak mulia, sehat, berilmu, cakap, kreatif, mandiri dan mejadi warga Negara yang demokratis serta bertanggung jawab.

Jumlah Anak Jalanan Dari Tahun Ke Tahun Semakin Meningkat, Krisis Ekonomi Turut Memberikan Pengaruh Bagi Peningkatan Jumlah Anak Jalanan Yang Sangat Pesat. 
Peningkatan Jumlah Anak Jalanan, di beberapa Lokasi, Keberadaan anak jalanan ada dimana-mana Terutama Di kawasan pasar, jalan raya, plaza, terminal, tempat rekreasi, ataupun pusat hiburan lainnya. Tingginya angka putus sekolah yang dijumpai pada kelompok anak jalanan tidak jauh berbeda dengan kelompok anak jalanan secara umum atau anak-anak yang bekerja. Anak yang putus sekolah cenderung menghabiskan seluruh waktunya dijalanan. Sedangkan bagi anak yang masih bersekolah relatif terbatasi kegiatannya mesti pada perkembangannya dapat terpengaruh lingkungan pergaulan komunitas jalanan. Bila tidak diantisipasi, anak yang bersekolah dapat terdorong untuk keluar dari sekolah dan selanjutnya lebih banyak tinggal dijalanan. Anak adalah amanah sekaligus karunia tuhan yang maha esa, yang senantiasa yang harus dijaga karena dalam dirinya melekat harkat, martabat, dan hakhak sebagai manusia yang harus dijunjung tinggi.

Indonesia memiliki perhatian terhadap kesejahteraan anak yang mana tertulis di uu ri no.23 tahun 2002 tentang perlindungan anak bab iii pasal 13 (1) yang berbunyi "setiap anak selama dalam pengasuhan orangtua, wali, atau pihak lain manapun yang bertanggung jawab atas pengasuhan, berkak mendapat perlindungan dari perlakuan. Sebagai anak mestinya mereka memperoleh ruang dan waktu yang kondusif untuk perkembangan fisik maupun psikis secara wajar. Anak yang seharusnya mendapat perlindungan kini harus bersandar pada dirinya sendiri mulai dari makan, minum, istirahat dan bermain, berlindung hingga pada saat sakit sekalipun. Anak jalanan yang memiliki konsep diri yang positif akan mampu memandang, memahami, dan mengerti dirinya sendiri, baik yang berupa kelebihan maupun kekurangan, mereka mampu mengembalikan fitrah yang ada pada dirinya, sedangkan anak jalanan yang memiliki konsep diri yang negatif tidak akan mampu memandang, memahami, dan mengerti dirinya sendiri, bahkan cenderung mudah terpengaruh oleh teman sebayanya. Lubis, h., \& hodriani, h. (2016)

\section{DISCUSSION}

\section{Anak jalanan}

Menurut departemen sosial ri (2001:5), anak jalanan adalah anak yang menghabiskan sebagian besar waktunya untuk melakukan kegiatan hidup sehari-hari di jalanan, baik untuk mencari nafkah atau berkeliaran di jalan dan tempat-tempat umum lainnya. Anak jalanan mempunyai ciri-ciri, berusia antara 6 sampai dengan 18 tahun, melakukan kegiatan atau berkeliaran di jalanan, penampilannya kebanyakan kusam dan pakaian tidak terurus, mobilitasnya tinggi. Selain itu, direktorat kesejahteran anak, keluarga dan lanjut usia, departemen sosial (2001:30) memaparkan bahwa anak jalanan adalah anak yang sebagian besar waktunya dihabiskan untuk mencari nafkah atau berkeliaran di jalanan atau tempat-tempat umum lainnya, usia mereka berkisar dari 6 tahun sampain 18 tahun. Unicef mengaitkan anak jalanan adalah anak yang menghabiskan sebagian besar waktunya di jalanan untuk bekerja atau beraktifitas lain. Mereka tinggal di jalanan karena tercampakkan atau dicampakkan oleh keluargakeluarga yang tidak mampu menang-gung beban hidup, terdesak oleh kemiskinan dan kehancuran keluarga. Ketidakmampuan dan kondisi keluarga juga lingkungan secara 
Upaya konselor dalam mengatasi permasalahan anak jalanan

timbal balik jadi pemicu anak turun ke jalanan, dan berkembang jadi masalah sosial. Tjahjorini, s., sumardjo, s., slamet, m., susanto, d., \& gani, d. S. (2015).

Istilah anak jalanan pertama kali diperkenalkan di amerika selatan tepatnya di brazilia, dengan nama meninos de ruas untuk menyebut kelompok anak-anak yang hidup di jalan, dan tidak memiliki tali ikatan dengan keluarga . Namun di beberapa tempat lainnya, istilah anak jalanan berbeda-beda, seperti colombia mereka disebut gamin (urchin atau melarat) dan ehinehes (kutu kasur), di bolivia mereka disebut polillas (ngengat). Istilah-istilah tersebut sebenarnya menggambarkan bagaimana posisi anakanak jalanan ini dalam masyarakat. Riyadi, a. (2016)

UNICEF telah mengelompokkan 3 kelompok anak jalanan sebagai (i) Anak-Anak Jalanan Jalan (anak-anak lari dari keluarga mereka dan tinggal sendirian di jalan), (ii) Anak-anak Jalanan Jalan (anak-anak menghabiskan sebagian besar waktu siang mereka di jalanan yang menangkis untuk diri mereka sendiri, tetapi kembali ke rumah secara teratur) dan (iii) Anak-anak Keluarga Jalanan (anak-anak yang tinggal di jalanan dengan keluarga mereka). Anak-anak meninggalkan rumah mereka dan mengarah ke jalan karena kemiskinan, perselisihan antar-keluarga dan memikat modernitas yang mendapatkan hambatan dalam kelanjutan tren ini dalam struktur keluarga mereka yang sedang berlangsung, Aptekar L (1884).

Anak jalanan tidak harus merupakan produk dari kondisi kemiskinan tetapi merupakan akibat dari kondisi keluarga yang tidak cocok bagi perkembangan si anak, misalnya produk keluarga broken home, orangtua yang terlalu sibuk sehingga kurang memperhatikan kebutuhan si anak, tidak ada kasih sayang yang dirasakan anak. Ketidak kondusifan tersebut memicu anak untuk mencari kehidupan di luar rumah, apa yang tidak ia temukan dalam lingkungan keluarga. Mereka hidup di jalan-jalan dengan melakukan aktifitas yang dipandang negatif oleh norma masyarakat.

Rata-rata mereka membentuk komunitas dan kelompok sosial tersendiri di luar kelompok masyarakat. Komunitas dan kelompok sosial tersendiri itu biasanya berbentuk Geng. Geng tersebut berfungsi sebagai keluarga bayangan bagi anak-anak yang bermasalah. Mereka merasa mendapatkan apa yang tidak didapat dalam keluarga. Kelompok sosial tersebut juga melahirkan sebuah strata sendiri.

\section{Permasalahan Anak Jalanan}

Anak-anak dan remaja dalam situasi jalanan (CASS) di negara-negara berpenghasilan rendah dan menengah (LAMIC) boleh dibilang dapat dianggap sebagai kelompok anak-anak yang paling berisiko untuk gangguan kesehatan mental dan psikososial dibandingkan dengan kelompok anak-anak lainnya. CASS, anak-anak jalanan dan anak jalanan adalah beberapa istilah yang digunakan untuk menggambarkan kelompok anak-anak ini yang memiliki hubungan dengan jalan; seperti tinggal, bekerja atau berkeliaran untuk waktu yang lama di jalanan. Anak-anak ini sering digambarkan sebagai 'tidak bersuara'; sekelompok anak-anak rentan yang mengalami cukup banyak kesulitan sejak usia muda. Harmaini, H. (2018).

Faktor-faktor ini pada gilirannya mempengaruhi pencapaian pendidikan, akses ke dukungan finansial, prospek pekerjaan, pengembangan hubungan positif, serta pengembangan moral dan nilai-nilai. Faktor-faktor ini ketika digabungkan pada akhirnya 
meningkatkan kerentanan anak terhadap kehidupan yang miskin. Setelah berada di jalanan, anak-anak ini dapat mengalami pelecehan dan kesulitan yang terus menerus yang dapat meningkatkan risiko putus asa, depresi, kurangnya harga diri, gangguan kejiwaan, masalah emosional dan perilaku yang serius, perilaku mencelakakan diri dan bunuh diri. (Myburgh, Moolla, \& Poggenpoel, 2015).

Ketidakmampuan dan kondisi keluarga juga lingkungan secara timbal balik jadi pemicu anak turun ke jalanan, dan berkembang jadi masalah sosial. Kepadatan penduduk yang tinggi diasosiasikan dengan kematian dan kelahiran yang tinggi, tekanan-tekanan di dalam rumah, kurang efektifnya perhatian terhadap anak dan timbulnya kenakalan anak-anak, juga munculnya masalah lain yang menyertai. Berbagai upaya untuk menangani keberadaan anak jalanan telah dilakukan pemerintah. Salah satunya dengan mengeluarkan kebijakan terkait perlindungan dan hak anak.

berdasarkan intruksi presiden no 3 tahun 2010 tentang pembangunan program yang berkeadilan, ditetapkan sebuah program kesejahteraan sosial anak (pksa) sebagai program prioritas nasional, yang didalamnya termasuk program kesejahteraan sosial anak jalanan (pks-anjal) dengan lembaga kesejahteraan sosial anak (lksa) sebagai wadah yang melaksanakan program kesejahteraan sosial anak jalanan. Anak jalanan (anjal) lebih mudah tertular kebiasaan tidak sehat dari kultur jalanan khususnya seks bebas dan penyalahgunnan obat. Sedihnya seringkali anak jalanan tidak merasa dieksploitasi mendapat kekerasan baik secara fisik, psikis maupun seksual. . Lubis, h., \& hodriani, h. (2016)

Mereka justru menganggap jalanan sebagai "lahan bermain" yang menyenangkan yang tidak banyak aturan. Belum lagi dijalan rata-rata mereka memiliki pengalaman buruk dengan satuan polisi pamong praja. Penanganan yang serinag dilakukan oleh pemerintah lebih bersifat sementara dan dengan tindak kekerasan yang menimbulkan trauma. Anak jalanan (anjal) yang direkrut diharuskan mengejar target penghasilan sejumlah uang dari profesi seperti itu, jelasnya kalau ternyata mereka tidak dapat melampaui jumlah yang dimaksud, terpaksa memilih cara lain dengan mengemis dan lain sebagainya. Kegiatan ini sangat berbahaya bagi pertumbuhan dan keselamatan anak itu sendiri, tatkala sejak awal diluar batas kesadarannya ia digiring dalam dunia kerja yang belum sanggup ia pikul. Riyadi, a. (2016).

Selanjutnya akan terbiasa dengan uang, mulai terbiasa merokok bagi anak laki-laki, melkukan penyalahgunaan zat baik narkoba maupun zat hirup. Anak-anak yang diperdagangkanuntuk tujuan ekonomi akan kehilangan waktu belajar, bermain dan berfantasi yang sebenarnya menjadimilik mereka. Waktu luang mereka telah dirampas pada usia yang sangat dini. Orientasi hidup mereka telah dibentuk sejak kecil untuk mengartikan hubungankemanusiaan sebagai hubungankontrak antara pihak yang membutuhkan dan diri merek sendiri. Tangan-tangan kecil mereka telah dibiasakan untuk mengerjakan sesuatu pekerjaan yang selayaknya dilakukan oleh orang dewasa. Lubis, h., \& hodriani, h. (2016).

Jelaslah bahwa kenakalan anak jalanan bukanlah suatu atau keadaan yang berdiri sendiri tetapi merupakan perpaduan dari beberapa kondisi yang di alami anak-anak jalanan. Jika dalam pertumbuhan dan perkembangan anak kurang mendapat pendidikan 
Upaya konselor dalam mengatasi permasalahan anak jalanan

dan pengarahan yang penuh tanggung jawab dari kedua orang tua mereka, maka kenakalan anak jalanan merupakan akibat yang tidak bisa dihindarkan lagi. Keluarga dan lingkungan tempat tinggal merupakan dua wilayah terdekat dari anak yang memiliki pengaruh yang signifikan dalam perkembangannya sebagai manusia. Dalam keluarga dan lingkungan tempat tinggal, terdapat fungsi dan nilainilai tertentu yang di anut, yang merupakan bagian dari konstruksi sosial yang berlaku di wilayah atau komunitas tertentu. Dengan demikian, seorang anak tidak pernah hidup dan tumbuh dalam ruang "vakum nilai dan fungsi", melainkan dalam udara nilai dan fungsi yang menafasi kehidupan keluarga dan masyarakat sekitarnya. Keluarga menjalankan peran tertentu terhadap anak dan mengajarkan nilai sosial dan budaya yang berlaku dalam masyarakatnya. Agar kehadiran anak dapat diterima di lingkungan di mana mereka tinggal masyarakat mengembangkan nilai sosial-budaya tertentu sebagai alat untuk menjalankan fungsinya, dan menjadikan ilai sosial-budaya tersebut sebagai rambu komunitas yang tinggal di dalamnya guna menjalankan perilaku tertentu.

Irwanto (1999) bahwa pemahaman terhadap situasi anak jalanan saja tidak akan memberikan jalan keluar yang efektif untuk mengatasi permasalahan anak jalanan. Agar sebuah intervensi efektif, maka diperlukan pemahaman yang menyeluruh mengenai masyarakat dan keluarga-keluarga anak jalanan. Pemahaman makro (struktural) dan mikro (dinamika keluarga) sangat dibutuh-kan.

Secara mental anak-anak jalanan tidak punya harapan hidup masa depan, bagi mereka bisa bertahan hidup saja sudah cukup. Kehidupan mereka harus berhadapan dengan realita di jalan yang penuh dengan resiko dan tantangan. Anak jalanan sering dicap sebagai anak nakal, biang kerusuhan, biang onar dan pernyataan-pernyataan miring lainnya. Perkataan-perkataan itu tentunya akan membawa dampak psikis bagi anak. Selain masalah pribadi sehari-hari di jalanan, perkawanan dan pekerjaan, anak jalanan secara langsung menerima pengaruh lingkungan dari keluarga maupun jalanan tempat ia berada.

Menurut Departemen Sosial RI (2002:13-15), aktivitas yang dilakukan anak jalanan di jalanan di antaranya adalah bekerja baik itu mengamen, mengemis, memulung, menjual koran, mengasong, mencuci bus, menyemir sepatu, menjadi calo, dan menggelandang. Selain itu Badan Kesejahteraan Sosial Nasional (2000: 61-62) menyebutkan bahwa beberapa aktivitas yang dilakukan oleh anak jalanan adalah bekerja sebagai pengamen, pemulung, pengemis, penjual koran, pengasong, pencuci bus, penyemis, maupun calo dan menggelandang.

Dari berbagai sumber di atas, dapat disimpulkan bahwa ada beberapa macam aktivitas anak yang dilakukan di jalanan di antaranya adalah untuk bekerja maupun sekedar menggelandang. Aktivitas bekerja anak jalanan di antaranya adalah menyemir sepatu, mengasong, menjadi calo, menjajakan koran atau majalah, mengelap mobil, mencuci kendaraan, menjadi pemulung, pengamen, menjadi kuli angkut, menyewakan payung, dan menjadi penghubung atau penjual jasa.

\section{Upaya Konselor dalam mengatasi permasalahan anak jalanan}

Konselor dituntut untuk kreatif dalam melakukan pendekatan dengan anak jalanan, dalam pendekatan awal misalnya. Konselor harus memberikan kesan positif pertama dalam melakukan perkelanan karena sifat anak jalanan sangatlah sensitif mengingat 
situasi kondisi lingkungan yang mereka hadapi sehari-hari. Konselor harus bisa membimbing anak jalanan untuk menemukan jati dirinya, anak jalanan memiliki bakat yang terampil namun mereka belum menyadarinya. Dengan melakukan bimbingan kelompok dan konseling individual, kemudian dengan melakukan kerja sama dengan dinas sosial atau rumah singgah sehingga kehidupan anak jalanan mendapatkan tempat yang layak, dan kreatifitas mereka dapat berkembang dengan baik yang tadinya kehidupan mereka kest- menjadi kes.

Masa remaja merupakan rentangan usia yang diliputi oleh ketidak stabilan jiwa anak, oleh karena itu berkaitan erat dengan juvenile delinquent (kenakalan remaja). Kaitan psikologis tersebut sejalan dengan kondisi lingkungan, akan tetapi yang kedua lebih dominan mendorong anak remaja menjadi delinquent. Kondisi lingkungan tersebut dapat bermula dari internal lingkungan keluarga, proses pendidikan di sekolah dan kelompok sosial, serta beberapa kondisi lain yang tidak menguntungkan perkembangan mental anak. Kaitan lain adalah pergaulan yang tidak sehat dengan teman-taman sebaya, pendidik, dan semua pihak yang terlibat dalam ikatan formal proses belajar mengajar sekolah, juga diperkuat oleh kondisi lingkungan yang tidak menguntungkan.

Lembaga perumahan menyediakan lingkungan yang aman dan bersih bagi ratusan anak-anak yang mungkin tidur di selokan, mandi di sungai yang tercemar dan meminta makanan dan uang. Sementara di tempat penampungan ini, psikolog klinis dapat menawarkan anak-anak psikoedukasi, penilaian psikologis, terapi kelompok dan bantuan dalam menyelesaikan masalah pribadi. Mereka dapat mendukung pengembangan pribadi mereka dengan meningkatkan keterampilan yang pada akhirnya memperkuat nilai diri positif dan pandangan hidup yang lebih baik. Mereka mendorong anak-anak untuk kembali ke keluarga asal mereka dan mereka mendukung mereka dalam mencapai hal ini. Pendekatan ini telah terbukti efektif dalam mengembalikan anak-anak ke keluarga asal mereka di Brasil dan Peru (Harris, Johnson, Young, \& Edwards, 2011). Jadi adanya kerja sama antara dinas sosial dan pemerintah setempat untuk membuat rumah singgah sehinggah anak jalanan bisa mendapatkan pendidikan dan tempat tinggal yang layak.

Salah satu upaya untuk mengatasi dampak tersebut terhadap kesejahteraan sosial anak pemerintah mengembangkan program pemberdayaan anak jalanan bekerja sama dengan lembaga swadara masyarakat $(\mathrm{lsm})$ melalui pendekatan rumah perlindungan sosial anak. Hal ini didasari karena anak sebagai generasi penerus adalah pewaris citacita perjuangan bangsa yang merupakan sumber daya manusia (sdm) yang sangat penting dalam mencapai keberhasilan pembangunan untuk menjadi sdm yang berkualitas, riyadi, a. (2016). Anak juga berhak atas peluang dan dukungan untuk mewujudkan dan mengembangkan diri dan kemampuannya. Di sisi lain kesulitan anak jalanan untuk mewujudkan, mengembangkan diri dan kemampuannya menyebabkan banyak kebimbangan, kebingungan, kecemasan dan konflik baik konflik eksternal yang terbuka, maupun internal dalam batin sendiri yang tersembunyi dan tertutup sifatnya. Sebagai dampaknya anak lalu mengembangkan pola tingkah laku menyimpang dari norma-norma umum dengan cara berbuat semaunya sendiri demi keuntungan sendiri. 


\section{CONCLUSIONS}

Berdasarkan pada pembahasan di atas, maka dapat disimpulkan bahwa hendaknya adanya kerjasama anatara pemerintah setempat untuk membuat rumah singgah untuk anak jalanan, agar pendidikan mereka lebih baik lagi dan kenyamanan hidup lebih baik. Kemudian dukungan dari teman, keluarga dan masyarakat juga diperlukan agar mereka bisa termotivasi untuk menjalani kehidupan yang layak dan baik dan mereka menemukan jati dirinya.

\section{REFERENCES}

Amin, M. A., Krisnani, H., \& Irfan, M. (2016). Pelayanan Sosial Bagi Anak Jalanan Ditinjau Dari Perspektif Pekerjaan Sosial. SHARE: Social Work Journal, 4(2).

Aptekar L (1884) Street Children in the Developing World: A review of their condition. Cross Cultural Research, 28 (30): 195-224.

Badan Kesejahteraan Sosial Nasional (BKSN). 2000. Modul Pelatihan Pimpinan Rumah Singgah. Jakarta: BKSN

Departemen Sosial RI dan UNDP (BKSN). 2002. Jakarta.

Departemen Sosial RI. 2001. Panduan Umum Program Kesejahteraan Sosial Anak. Jakarta: Menteri Sosial Republik Indonesia.

Hakim, M. A., \& Rahman, A. (2016). Health And Nutritional Condition Of Street Children Of Dhaka City: An Empirical Study In Bangladesh. Science Journal Of Public Health, 4(1-1), 6-9.

Harmaini, H. (2018). Tipe Kepribadian dan Aktivitas Anak Jalanan. Jurnal Psikologi, 7(1), 91-105.

Harris, M.S., Johnson, K., Young, L., \& Edwards, J. (2011). Community reinsertion success of street children programs in Brazil and Peru. Children and Youth Services Review, 33, 723-731.

Hatley A, Huser A. (2005) Identification of Street Children: Characteristics of street children in Bamako and Acca. FAFO Report 474.

Irwanto. 1996. Pekerja Anak di Tiga Kota Metropolitan: Jakarta, Surabaya dan Medan. Jakarta: Pusat Penelitian Atmajaya

Lubis, H., \& Hodriani, H. (2016). Profil Kehidupan Anak Jalanan Di Kota Pematangsiantar. JPPUMA: JURNAL ILMU PEMERINTAHAN DAN SOSIAL POLITIK UMA (JOURNAL OF GOVERNANCE AND POLITICAL SOCIAL UMA), $4(1), 107-119$.

Myburgh, C., Moolla, A., \& Poggenpoel, M. (2015). The lived experiences of children living on the streets of Hillbrow. Curationis, 38, 1274-1281.

Prasetyo, H. P., \& Umuri, M. T. (2017). Pembinaan Moral Anak Jalanan Di Rumah Singgah Ahmad Dahlan Yogyakarta. Jurnal Citizenship: Media Publikasi Pendidikan Pancasila Dan Kewarganegaraan, 3(1), 57-72.

Riyadi, A. (2016). HUBUNGAN KONSEP DIRI DENGAN KENAKALAN ANAK JALANAN PADA RUMAH SINGGAH PUTRA MANDIRI SEMARANG. Psympathic: Jurnal Ilmiah Psikologi, 3(1), 23-34.

Subramanyam, Y. S. (2016). Child porters: Psychosocial profile of street children. The Indian Journal of Social Work, 51(4), 577-582. 
Susilowati, D. (2017). KEBIJAKAN PENANGGULANGAN ANAK JALANAN DI KOTA MALANG. Research Report, 884-889.

Tjahjorini, S., Sumardjo, S., Slamet, M., Susanto, D., \& Gani, D. S. (2015). Perilaku Anak Jalanan Dan Strategi Pengentasannya Di Bandung, Bogor, Dan Jakarta. Jurnal Penyuluhan, 5(1).

Undang-Undang nomor 20 tahun 2003 tentang system pedidikan nasional. 